\title{
National expenditure on health research in South Africa: How has the landscape changed in the past decade?
}

\author{
M A Barnabé, ${ }^{1}$ MSc (Med); R Gordon, ${ }^{2,3,4}$ PhD; G Ramjee, ${ }^{2,5}$ PhD; G Loots, ${ }^{2,6}$ MHSc; J M Blackburn, ${ }^{1,2,7}$ DPhil \\ ${ }^{1}$ Department of Integrative Biomedical Sciences, Faculty of Health Sciences, University of Cape Town, South Africa \\ ${ }^{2}$ National Health Research Committee, Department of Health, Pretoria, South Africa \\ ${ }^{3}$ South African Medical Research Council, Cape Town, South Africa \\ ${ }^{4}$ Centre of Excellence in Pharmaceutical Sciences, North-West University, Potchefstroom, South Africa \\ ${ }^{5}$ Aurum Institute, Johannesburg, South Africa \\ ${ }^{6}$ Department of Science and Innovation, Pretoria, South Africa \\ Institute of Infectious Disease and Molecular Medicine, Department of Integrative Biomedical Sciences, Faculty of Health Sciences, \\ University of Cape Town, South Africa
}

Corresponding author: J M Blackburn (jonathan.blackburn@uct.ac.za)

\begin{abstract}
Background. Over the past 18 years, the South African (SA) Ministry of Health has committed to allocate $2 \%$ of the national health budget to research, while the National Health Research Policy (2001) proposed that the health research budget should be $2 \%$ of total public sector health expenditure. A review was conducted by the National Health Research Committee (NHRC) in 2014 to determine whether these goals had been met, using available data up to 2009/10. It revealed that public sector health research funding remained below $2 \%$ of the national health budget, supporting the perception of reduced public sector health research funding.

Objectives. To provide an update on the previous review to investigate changes in the health research landscape since 2009/10 and whether goals have been met.

Methods. Various publicly available sources of information on public and private expenditure on health research in SA were used to investigate health research funding and expenditure. In addition, questionnaires were sent to 35 major national and international funders of health research in SA to obtain data on the level of funding provided and the fields of research funded.

Results. Total health research expenditure in SA was ZAR6.9 billion in 2016/17, or 19.2\% of gross expenditure on research and development, with 1.7\% of the ZAR38.6 billion National Department of Health budget from National Treasury being spent on health research through the South African Medical Research Council (ZAR658 million), corresponding to $0.4 \%$ of the consolidated government expenditure on health. However, although the total government plus science council spend on health research in 2016/17 was ZAR1.45 billion, this represents just $0.033 \%$ of the gross domestic product (GDP), thus remaining well below the aspirational target of $0.15 \%$ of the GDP set by the NHRC in 2014. Based on feedback from the funders, the estimated baseline health research funding in 2016/17 was in excess of ZAR4.1 billion, which is considerably higher than many researchers may realise. Three-quarters of this funding originated from foreign sources, suggesting both strengths and opportunities for health research in SA, but also highlighting increasing dependence on foreign funding. Notably, the majority of funders approached were not able to readily break down expenditure according to disease area.

Conclusions. Health research funding has changed significantly since our previous review, although the government's own commitments to it remain unmet. Improved mechanisms to track health research expenditure are urgently required for better alignment of funding priorities and increased co-ordination between science councils in health research funding.
\end{abstract}

S Afr Med J 2020;110(4):274-283. https://doi.org/10.7196/SAMJ.2020.v110i4.14349

Health research is an area of innovation that contributes significantly to a country's growth and development, as it drives the performance of health systems and boosts the economy by ensuring the increased health, and thereby productivity, of the population, as well as through direct contributions to the bioeconomy and job creation. Adequate funding for health research is particularly important in the context of South Africa (SA), as innovation is needed in the development and translation of new diagnosis, treatment and vaccine strategies, as well as in health systems, public health, epidemiology, biostatistics, health economics, sociology of health, medical anthropology and occupational health, among others. Through the Mexico (2004), ${ }^{[1]}$ Bamako (2008) ${ }^{[2]}$ and Algiers (2008) ${ }^{[3]}$ declarations, the SA Ministry of Health has committed to allocate $2 \%$ of the national health budget to research, while the National Health Research Policy $(2001)^{[4]}$ proposed that the country's budget for health research should be $2 \%$ of total public sector health expenditure. In addition, the Academy of Science of South Africa (ASSAf) recommended that gross expenditure on research and development (GERD) should be $2 \%$ of the gross domestic product (GDP), and that $0.4 \%$ of the GDP should be spent on health research across all sectors. ${ }^{[5]}$

The National Health Research Committee (NHRC) performed a spending review in 2014 to determine whether these goals had been met. ${ }^{[6]}$ Based on available data up to $2009 / 10$, the review revealed that public sector funding allocated to health research in SA remained below the goal of $2 \%$ of the national health budget, supporting the perception of a progressive reduction in public sector health research funding between 2006 and 2010. Furthermore, the 2014 review highlighted the lack of clarity and transparency with regard to the allocation of funds, as well as in the interpretation of various commitments made by the SA government, emphasising the need to develop efficient mechanisms to monitor health funding expenditure by both governmental (SA and international) and private sector funders according to well-defined international benchmarks. Accordingly, the NHRC recommended that the SA government adopt the World Health Organization (WHO)'s 
target of $0.15 \%$ of GDP spending on government investment in health research as a tangible and transparent aspiration.

\section{Objectives}

During the 7 years that separate the 2009/10 data used in the 2014 review and the latest complete data available (2015/16), the health funding landscape in SA has changed dramatically, including a significant increase in funds invested by foreign governments and agencies. In this article, as an update to the 2014 analysis, we provide an overview of the current state of health funding in SA in order to determine the quantum and sources of funding currently available to health researchers in SA, as well as to investigate funding allocation as a function of disease area.

\section{Methods \\ Sources of information}

Several publicly available sources of information on public and private expenditure on health research in SA were used, including the national surveys of research and experimental development of the Department of Science and Technology (DST) $\left(2009 / 10^{[7]}\right.$ and $\left.2016 / 17^{[8]}\right)$, National Treasury's estimates of national expenditure $\left(2013,{ }^{[9]} 2014,{ }^{[10]} 2017^{[11]}\right.$ and $\left.2018^{[12]}\right)$, National Treasury's mediumterm budget policy statements $\left(2010,{ }^{[13]} 2012^{[14]}\right.$ and $\left.2017^{[15]}\right)$, and the National Department of Health (NDoH) annual report (2016/17). ${ }^{[16]}$ In addition, questionnaires were sent to 35 major national and international funders of health research in SA (supplementary Table S1, available at http://www.samj.org.za/public/sup/14349.doc) in late 2017, asking them to provide non-confidential, aggregated secondary data on funding awards in SA, including: (i) the level of funding provided; and (ii) if available, the fields of research to which the funding was allocated. This questionnaire deliberately excluded funding for clinical trials conducted by multinational pharmaceutical companies, as well as any private health research being conducted. Where possible, we also excluded indirect cost recovery and capacity development grants. Subgrants made from one SA institution to another were not included in order to minimise double counting. Using the annualised data provided, we estimated the total funding available for health research in 2016/17.

\section{Metrics and definitions}

For the purposes of this study, we used the proportion of GERD allocated to health research and GERD as a proportion of GDP as surrogate indicators of total health expenditure on research in SA. Furthermore, we used consolidated government expenditure on health as a proxy for the national health budget, and the health vote as a proxy for the NDoH budget. Definitions for terms used are listed in Table 1 . We have used the term 'health research' throughout, noting that this includes, but is not limited to, public health, epidemiology, biostatistics, health systems and policy research, health economics, sociology of health, medical anthropology and occupational health, as well as clinical and biomedical research and innovation, consistent with the 'research for health' $(\mathrm{R} 4 \mathrm{H})$ terminology adopted by the WHO in 2012. ${ }^{[17]}$

\section{Results}

\section{Research and development expenditure} Total GERD

Our previous evaluation of GERD between 1991 and 2009 revealed a steady increase in expenditure from <ZAR4 billion in 1991 to ZAR20.9 billion in 2009/10, representing approximately a two-fold increase in real terms once inflation is considered. ${ }^{[6]}$ Although GERD stagnated between 2008/09 and 2010/11 (possibly as a result of the 2008 financial crisis), we observed a subsequent increasing trend between 2010/11 and 2016/17 (Fig. 1). Between 2009/10 (ZAR20.9 billion) and 2016/17 (ZAR35.7 billion), an average annual

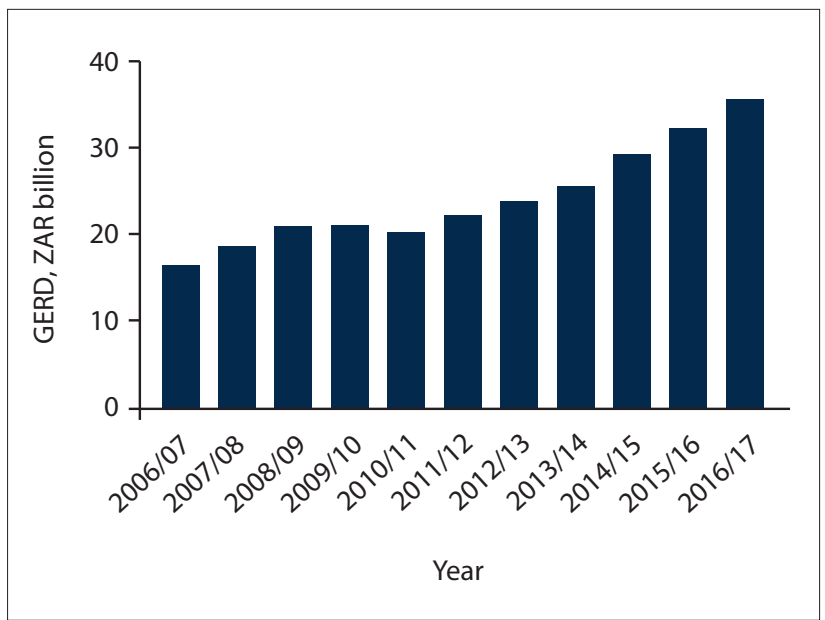

Fig. 1. GERD for SA from 2006/07 to 2016/17 (GERD = gross expenditure on research and development; $S A=$ South Africa.)

Table 1. Definitions of terms and metrics used ${ }^{[8]}$

Gross domestic product (GDP) The total market value of all final goods and services produced in a country in a given year, equal to total consumer, investment and government spending, plus the value of exports, minus the value of imports

Research and experimental development (R\&D)

Gross expenditure on research and development (GERD) Creative work undertaken on a systematic basis in order to increase the stock of knowledge, including knowledge of man, culture and society, and the use of this stock of knowledge to devise new applications All expenditures for R\&D performed on national territory in a given year. This includes domestically performed R\&D which is financed from abroad but excludes R\&D funds paid abroad, notably to international agencies

Business enterprise sector

Government sector All size classes of enterprises, including state-owned enterprises in SA

Higher education sector Departments in the three spheres of national, provincial and local government in SA with an R\&D component, government research institutions, and museums

Not-for-profit (NPO) sector All public higher education institutions and private higher education institutions in SA with an R\&D component

Science council sector

Non-governmental and other organisations formally registered as not-for-profit institutions in SA Comprising the nine SA science councils established through Acts of Parliament

SA = South Africa/n 
increase of $7.95 \%$ therefore occurred, or $2.3 \%$ per annum in real terms, once the average inflation rate over this period (5.64\%) is considered. According to the DST's 2015/16 national survey, a noteworthy portion of this increase in GERD was driven by improved responses in the higher education sector.

Although GERD increased in real terms over this period, the percentage of the GDP allocated to research and experimental development (R\&D) did not (Fig. 2A). In 2009/10, GERD was $0.89 \%$ GDP and decreased until 2013/14 when it reached $0.72 \%$ GDP, the lowest it has been since 1997, before increasing slightly over the next 4 years to $0.82 \%$ in $2016 / 17$. GERD has therefore remained persistently below $1 \%$ GDP and far below the ASSAf recommendation of $2 \%$ GDP $^{[5]}$ A comparison of the percentage of the GDP spent on R\&D in SA with that spent in various lowermiddle-income, upper-middle-income and high-income countries (LMICs, UMICs and HICs, respectively) (Fig. 2B) revealed that India, an LMIC that spent $0.71 \%$ GDP on R\&D in 2004, has now overtaken SA by spending $0.85 \%$ GDP in 2015, with Russia (1.13\% GDP), Brazil (1.17\% GDP) and China (2.11\% GDP) further ahead, leaving SA the BRICS (the acronym coined for an association of five major emerging national economies: Brazil, Russia, India, China and SA) country spending the lowest proportion of its GDP on R\&D. GERD in countries with established industrialised economies ranged between $1.6 \%$ and $4.3 \%$ GDP, with Israel, Korea, Sweden, Japan, Germany and the USA leading the way. According to the United Nations Educational, Scientific and Cultural Organization (UNESCO), ${ }^{[18]}$ increased funding for $R \& D$ is strongly supported by business sector investment, as is reflected by the fact that $78.2 \%$ and $84.6 \%$ of Korea and Israel's R\&D funding, respectively, are provided by the business sector.

\section{GERD on health research}

The proportion of GERD allocated to health research in SA between 2006/07 and 2016/17 is shown in Fig. 3A. Driven by progressive increases year on year from 2007/08, 19.8\% GERD was spent on health research in 2015/16, followed by a slight decrease to $19.2 \%$ in $2016 / 17$, with the medical and health sciences now receiving the largest portion of GERD across all fields of research in SA. This percentage is now in line with the ASSAf recommendation that $20 \%$ of the country's total R\&D funding should be allocated to health research. ${ }^{[5]}$ In absolute terms, health research expenditure essen-
A

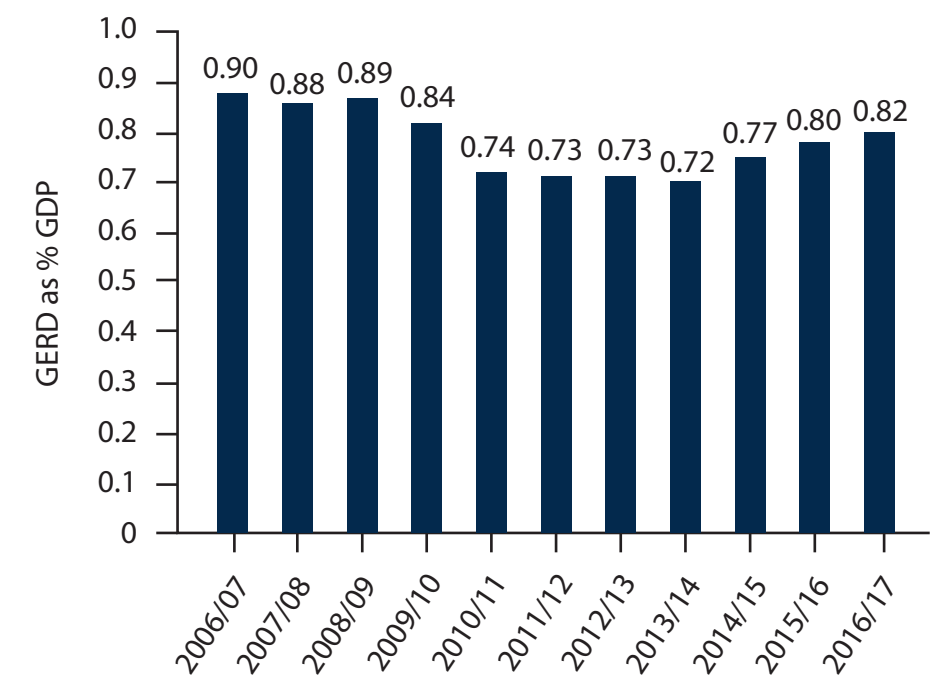

B

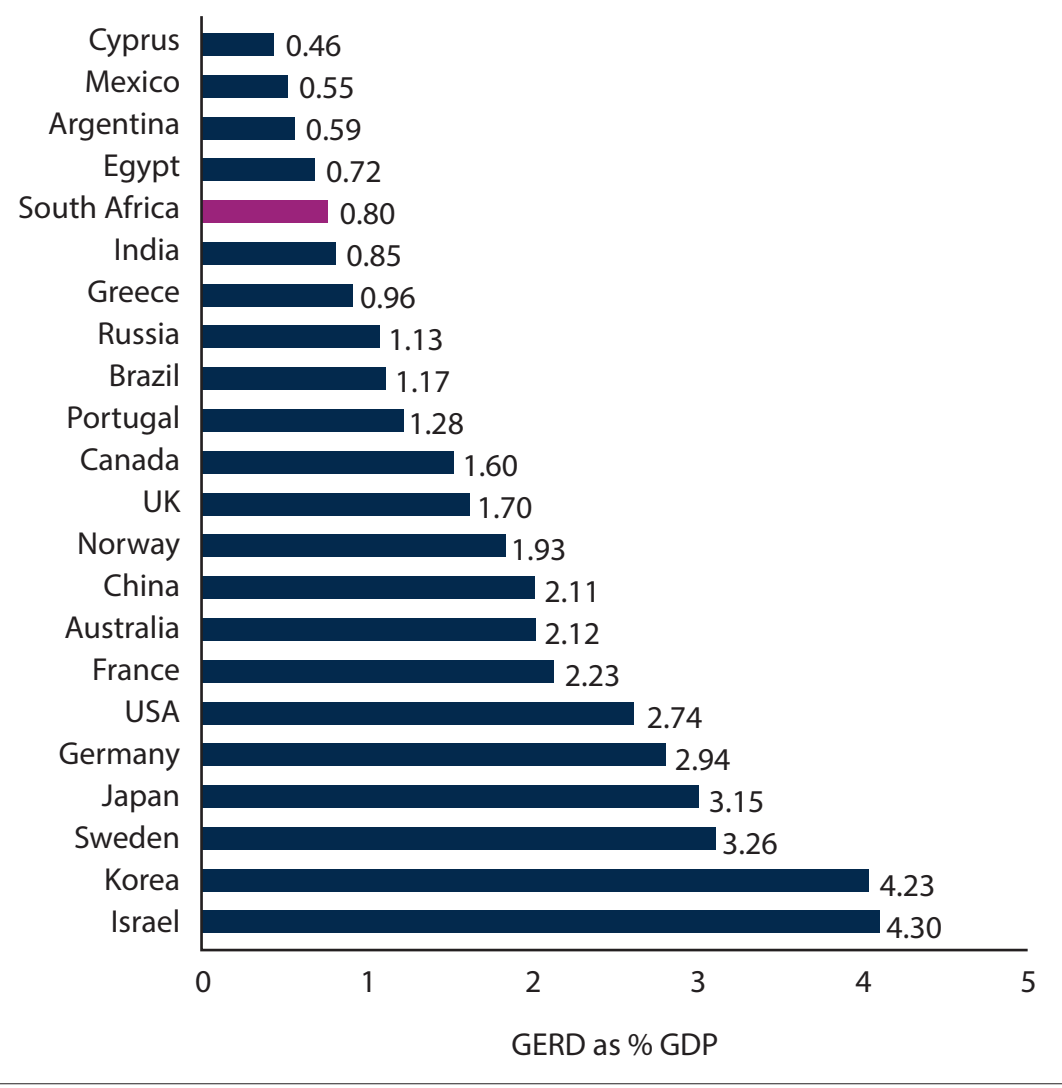

Fig. 2. (A) GERD as a percentage of the GDP for SA from 2006/07 to 2016/17; (B) GERD as a percentage of the GDP for various LMICs, UMICs and HICs. Data are for 2016 for USA, China, Japan and Germany; for 2015 for India, SA, Cyprus, Egypt, Korea, UK, France, Russia, Sweden, Mexico, Norway, Portugal, Greece and Israel; and for 2014 for Canada, Australia and Argentina. ${ }^{[17]}$ LMICs: Egypt and India; UMICs: Argentina, Brazil, China, Mexico, Russia and SA; HICs: Australia, Canada, Cyprus, France, Germany, Greece, Israel, Japan, Korea, Norway, Portugal, Sweden, UK and USA. $(G E R D=$ gross expenditure on research and development; $G D P=$ gross domestic product; $S A=$ South Africa; LMICs = lower-middle-income countries; UMICs = upper-middle-income countries; HICs = high-income countries.) 

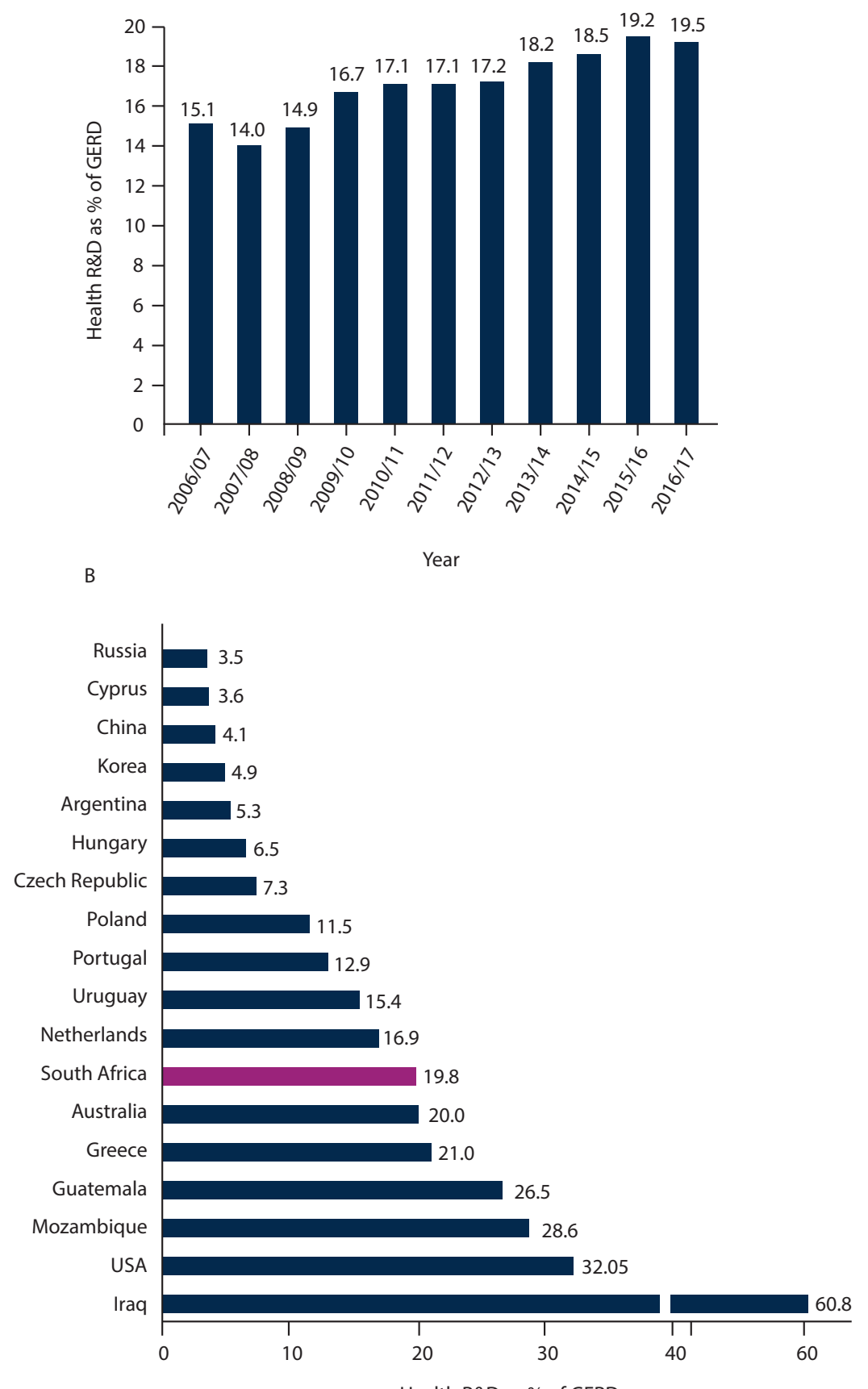

Fig. 3. (A) Percentage of GERD on health research in SA from 2006/07 to 2016/17; (B) Percentage of GERD on health research for various LICs, LMICs, UMICs and HICs. Data are for 2015 with the exception of China (2013) and Australia (2008). ${ }^{[17]}$ LIC: Mozambique; LMICs: Guatemala, Iraq; UMICs: Argentina, China, Russia and SA; HICs: Australia, Cyprus, Czech Republic, Greece, Hungary, Korea, Netherlands, Poland, Portugal, Uruguay and USA. (GERD = gross expenditure on research and development; SA = South Africa; LICs = low-income countries; LMICs = lower-middle-income countries; UMICs = upper-middle-income countries; HICs = high-income countries; R\&D = research and experimental development.)

tially doubled between 2009/10 (ZAR3.5 billion) and 2016/17 (ZAR6.9 billion), representing an absolute increase of $10.2 \%$ per annum and an average increase of $4.5 \%$ per annum in real terms.
Analysis of the percentage of GERD spent on health research in various low- to high-income countries (Fig. 3B) reveals that $\mathrm{SA}$ is now one of the countries that spends the biggest portion of its GERD on health research, far ahead of Russia (3.5\%) and China (4.1\%). Interestingly, several low-income countries and LMICs, such as Guatemala, Mozambique and Iraq, are spending very significant portions of their GERD on health research, with Iraq allocating a staggering $60.8 \%$ GERD to health research. In the future this may contribute to closing the '10/90 gap', a term coined by the Global Forum for Health Research almost 20 years ago to highlight the fact that only $10 \%$ of the world's resources for health research were focused on preventable diseases that affect $90 \%$ of populations in developing countries. ${ }^{[19,20]}$

\section{Health research expenditure in SA by sector}

The sources of health research expenditure in SA according to sector between 2006/07 and 2016/17 are shown in Fig. 4. Small, inflationary increases were observed in health research expenditure from the business sector (Fig. 4A) between 2009/10 and 2016/17. In contrast, higher education sector expenditure on health research (Fig. 4B) has grown steadily from ZAR710 million in 2006/7 to ZAR1 196 million in 2009/10 and ZAR2 413 million in 2016/17. This rise was largely driven by an increase in foreign funding and represents an average increase of $10.5 \%$ per annum in absolute terms and $4.9 \%$ in real terms since $2009 / 10$.

Government sector expenditure on health research (Fig. 4C) stagnated between 2006/ 07 and 2012/13 (ZAR212 million), but then almost tripled in 2013/14 (ZAR595 million). The mechanisms driving this sudden increase are unclear, but it may reflect changes in the reporting and classification of funding allocation (e.g. a funding item that was previously not classified as health research may have been incorporated into the health research classification in 2013). Similarly, science council internal $\mathrm{R} \& \mathrm{D}$ expenditure on health research (Fig. 4E) stagnated for several years at levels close to those of 2009/10 (ZAR441 million) before increasing significantly in 2014/15 and reaching ZAR837 million in $2016 / 17$. This sudden change may be attributed at least in part to the South African Medical Research Council (SAMRC) revitalisation plan, ${ }^{[21]}$ which came into effect at this time. Expenditure by notfor-profit organisations (NPOs) (Fig. 4D), which had been negligible prior to 2012, increased from ZAR17 million in 2011/12 to ZAR265 million in $2012 / 13$, reaching ZAR720 million in 2016/17. It is unclear whether this represents a real increase in expenditure, possibly driven by an influx of 

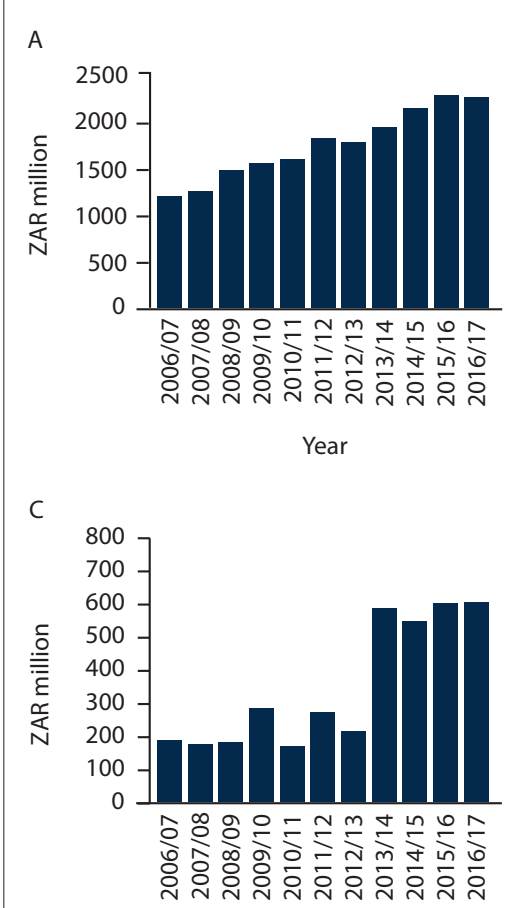

Year

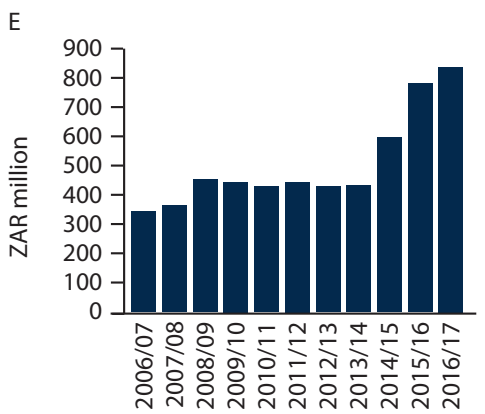

Year

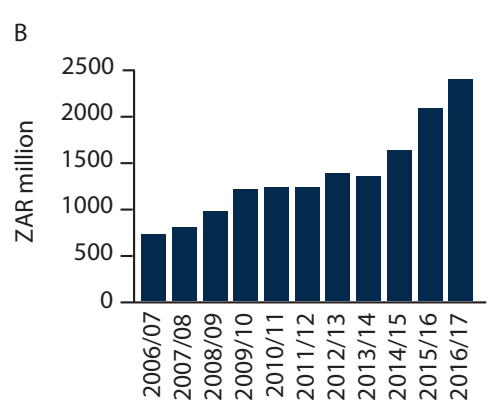

Year

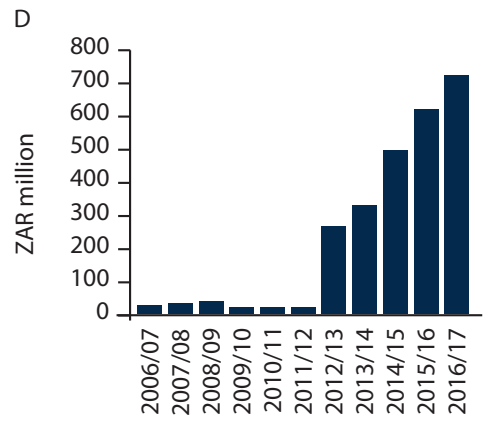

Year

Fig. 4. Health research expenditure by sector for the period 2006/07 - 2016/17 in SA. (A) Business sector; (B) Higher education sector; (C) Government; (D) Not-for-profit organisations; (E) Science councils. (SA = South Africa.)

foreign funding, or a change in the reporting and classification of expenditure by the DST in its more recent surveys. Further research is needed to determine this.

Interestingly, aggregated domestic government and science council spending on health research doubled from ZAR729.4 million in 2009/10 to ZAR1 452 million in 2016/17 (the latter figure comprising ZAR615.1 million from the government and ZAR836.9 million from the science councils), representing an average increase of $10.3 \%$ per annum (real increase of $4.7 \%$ per annum). Aggregated government sector spending now represents 4.1\% GERD (up from 3.5\% GERD in $2009 / 10$ ), although the percentage of the GDP has not changed significantly $(0.03 \%$ in $2009 / 10$ v. $0.033 \%$ in $2016 / 17$ ) and so still remains far below the NHRC's target of $0.15 \%$ GDP. $^{[6]}$

This analysis reveals that total expenditure on health research aggregated across the higher education, government, science councils and not-for-profit organisations totalled $\sim$ ZAR4.6 billion in 2016/17, up from $\sim$ ZAR1.9 billion in 2009/10, thus identifying an increasing national and international commitment to funding of health research in SA.

Proportion of the national health budget spent on health research

We previously proposed that the consolidated government expenditure on health be used as a proxy for the national health budget and that the health vote be used as a proxy for the NDoH's budget. Here, we now also use the SAMRC baseline government grant through the health vote as a proxy to estimate the NDoH's spending on health research. In 2016/17, the SAMRC baseline government grant (ZAR657.6 million) was $1.7 \%$ of the health vote (ZAR38.6 billion), representing a $47.5 \%$ increase in the SAMRC's baseline grant compared with that in 2014/15 (Table 2). In addition, since the NHRC has now adopted the broader WHO definitions of $\mathrm{R} 4 \mathrm{H}$, surveillance, occupational health and health systems research among others represent important components of health research. Thus, in 2016/17, the National Health Laboratory Service spent ZAR654 million of its transfer from the $\mathrm{NDoH}$ (ZAR712 million) on health research, while the Health Systems Trust spent ZAR12 million. ${ }^{[12]}$ Furthermore, according to the NDoH's annual report $(2016 / 17){ }^{[16]}$ the Health Information Research Monitoring and Evaluation programme of the $\mathrm{NDoH}$ spent ZAR55.8 million in 2016/17, while the NDoH's Health Information Systems programme spent ZAR12.7 million that year. Whether these latter two $\mathrm{NDoH}$ programmes truly represent expenditure on health research depends somewhat on definitions, but monitoring and evaluation does appear to fit within $\mathrm{R} 4 \mathrm{H}$. The total transfers by the NDoH through the Health Vote for R4H were therefore ZAR1 392 million in $2016 / 17$, representing $3.6 \%$ of the NDoH budget.

According to the Medium-Term Budget Policy Statement (2017) ${ }^{[15]}$ the nine provincial departments of health (pDoHs), Eastern Cape, Free State, Gauteng, KwaZulu-Natal, Limpopo, Mpumalanga, Northern Cape, North West and Western Cape, received a total of ZAR163.9 billion from Treasury in $2016 / 17$, more than four times the NDoH's budget of ZAR38.6 billion that year. ${ }^{[15]}$ However, when the NHRC met with the respective provincial health research committees in mid-2019, none reported having significant recurrent budgets for health research, and none was aware of any recurrent budgets for health research elsewhere in their pDoHs. Further research is therefore now underway to determine what funds, if any, are allocated by the $\mathrm{pDoHs}$ for health research on a recurrent basis. These data will be reported elsewhere.

\section{R\&D funding}

Gross R\&D funding sources by sector

R\&D in SA has multiple funding sources, both local and international. The funds provi- 
Table 2. Government sector expenditure on health

\begin{tabular}{|c|c|c|c|c|c|c|c|c|c|c|}
\hline & \multicolumn{10}{|c|}{ Government budget } \\
\hline & $2009 / 10$ & $2010 / 11$ & 2011/12 & $2012 / 13$ & 2013/14 & $2014 / 15$ & $2015 / 16$ & $2016 / 17$ & $2017 / 18$ & $2018 / 19^{*}$ \\
\hline $\begin{array}{l}\text { Consolidated } \\
\text { government } \\
\text { expenditure on } \\
\text { health (ZAR } \\
\text { billion) }{ }^{\dagger}\end{array}$ & 91.4 & 100.2 & 114.1 & 126.0 & 134.2 & 144.6 & 159.8 & 176.1 & 191.6 & 208.8 \\
\hline $\begin{array}{l}\text { Health vote (ZAR } \\
\text { billion) })^{\dagger}\end{array}$ & 17.0 & 21.7 & 25.7 & 27.6 & 30.7 & 34.4 & 35.9 & 38.5 & 42.4 & 47.0 \\
\hline $\begin{array}{l}\text { MRC baseline } \\
\text { government grant } \\
\text { through the health } \\
\text { vote ( } \mathrm{ZAR} \text { million) }{ }^{\ddagger}\end{array}$ & 251 & 270 & 271 & 284 & 416 & 446 & 624 & 658 & 615 & 625 \\
\hline $\begin{array}{l}\text { MRC baseline } \\
\text { government grant } \\
\text { as proportion } \\
\text { of consolidated } \\
\text { government health } \\
\text { expenditure, \% }\end{array}$ & 0.27 & 0.27 & 0.24 & 0.23 & 0.31 & 0.31 & 0.39 & 0.37 & 0.32 & 0.30 \\
\hline $\begin{array}{l}\text { MRC baseline } \\
\text { government grant, as } \\
\text { proportion of total } \\
\text { health vote, } \%\end{array}$ & 1.48 & 1.24 & 1.05 & 1.03 & 1.36 & 1.3 & 1.74 & 1.70 & 1.45 & 1.33 \\
\hline
\end{tabular}

ded by the SA government, the SA business sector and foreign funders (all sources) from 2006/07 to 2016/17 are shown in Fig. 5. After stagnating between 2009/10 (ZAR9.31 billion) and 2011/12 (probably owing to the 2008 financial crisis), government funding for R\&D increased steadily to ZAR16.43 billion in $2016 / 17$, representing an increase of $76 \%$ since $2009 / 10$ in absolute terms, or $2.8 \%$ per annum in real terms. However, business sector funding decreased from ZAR8.91 billion in $2009 / 10$ to ZAR8.13 billion in 2010/11 before increasing again to ZAR14.05 billion in $2016 / 17$, representing only a $1.1 \%$ increase per annum in real terms. The stagnation or decrease in government- and business-funded R\&D between 2008/9 and 2011/12 was one of the 'notable developments' reported in the DST's survey in 2015/16. Foreign funding for R\&D in SA increased from ZAR2.54 billion in 2009/10 to ZAR4.17 billion in 2016/17, representing an absolute increase of $64 \%$ (equivalent to $7.3 \%$ year on year) since $2009 / 10$, but only $1.7 \%$ per annum in real terms. Across government, business and foreign sectors, the limited growth in funding for R\&D in real terms since 2009/10 therefore appears to mirror the slow growth of the SA economy.

\section{Recipients of foreign funding for} R\&D by sector

Foreign funding of $\mathrm{R} \& \mathrm{D}$ in $\mathrm{SA}$ by sector is shown in Fig. 6A, which indicates that

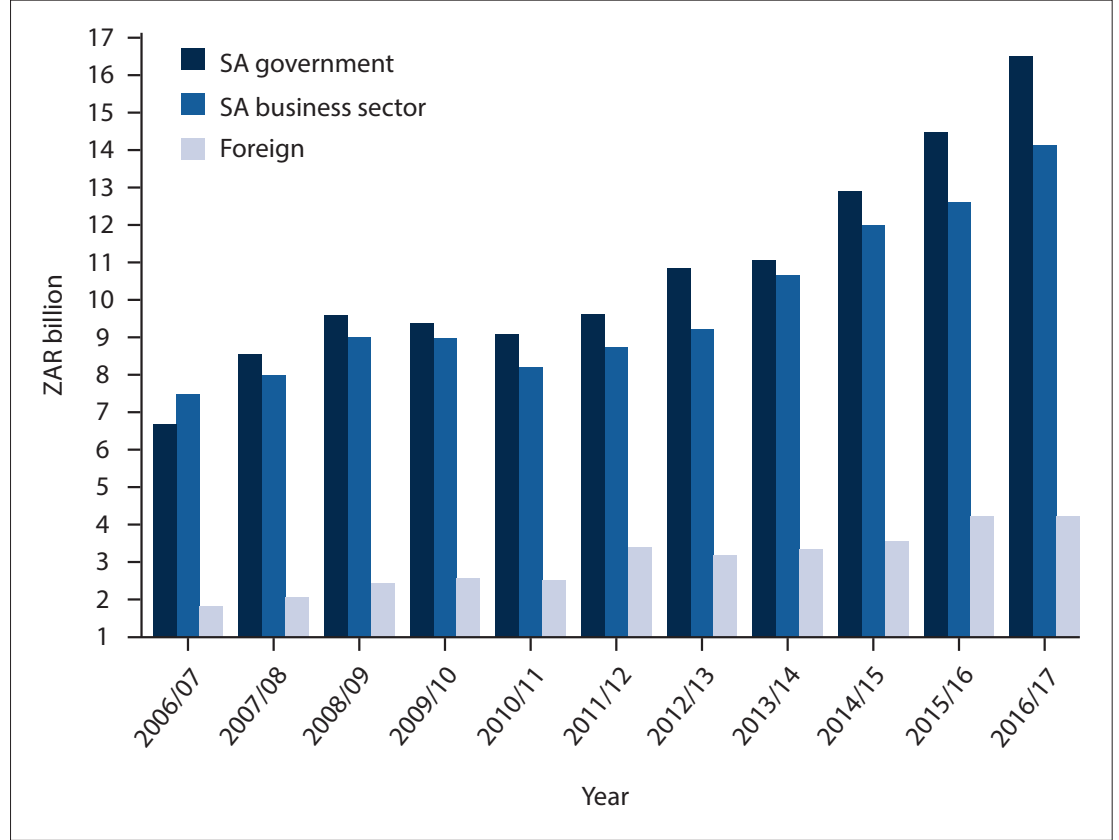

Fig. 5. Sources of R↔D funding in SA from 2006/07 to 2016/17. (RઐD = research and experimental development; $S A=$ South Africa; ${ }^{*}$ Government funding includes science council and university funds, as well as funds from higher education institutions, not-for-profit organisations, and individual donations disbursed to all sectors.)

the trends since $2009 / 10$ are not uniform across the sectors. In 2016/17, foreign funds for R\&D were primarily provided to the business and higher education sectors ( $32.1 \%$ and $27.4 \%$, respectively), followed by NPOs (15.3\%), science councils $(12.9 \%)$ and government (12.3\%). Notably, foreign funding of higher education R\&D increased more than four-fold in the past 10 years, from ZAR278 million in 2006/7 to ZAR443 million in 2009/10 and ZAR1.14 billion in 2016/17. Although funding almost tripled in 2011/12 alone, it has not increased since then. Government funds for $R \& D$ 


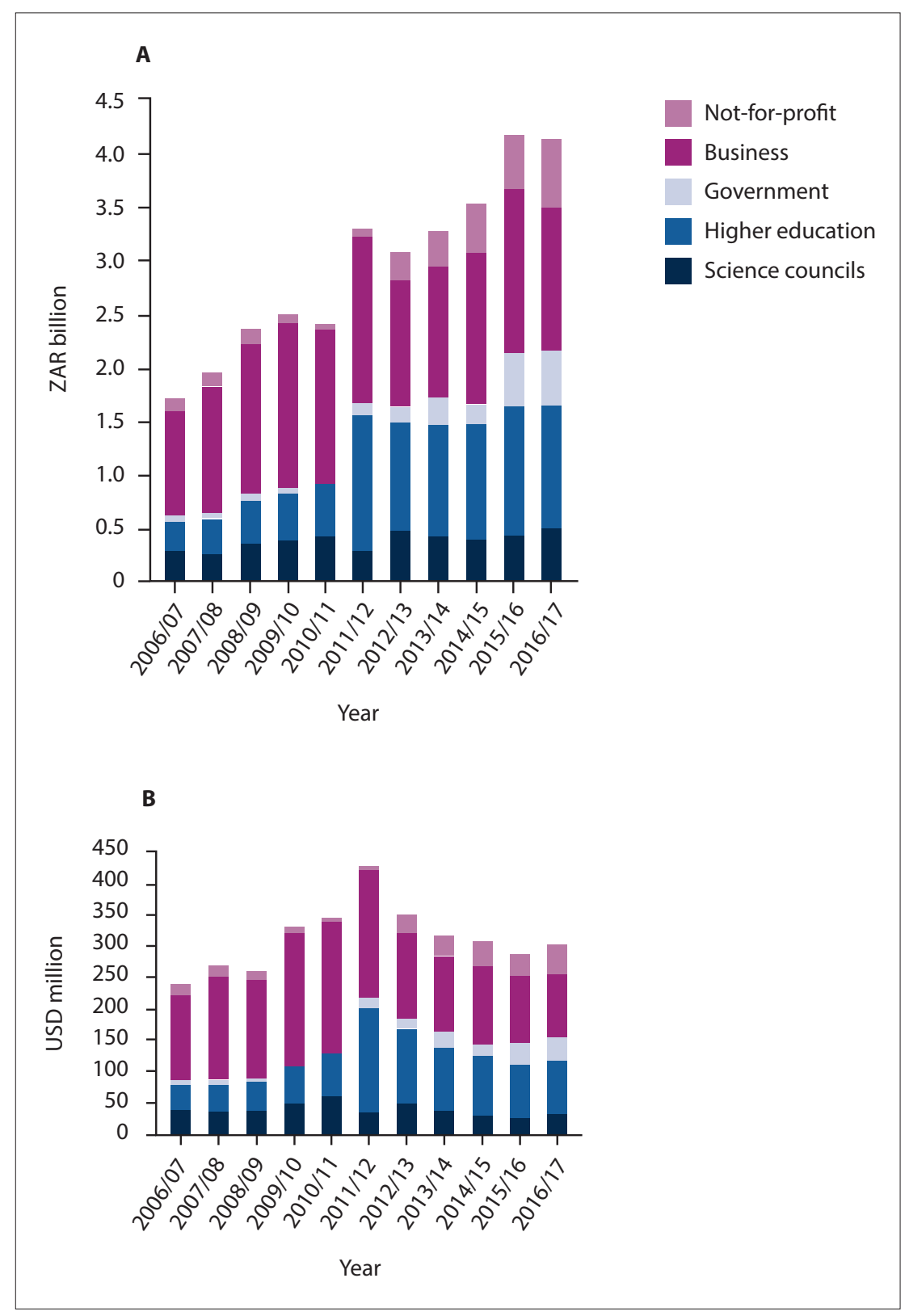

Fig. 6. Foreign funding of RઐD in SA by sector from 2006/07 to 2016/17 in ZAR (A) and USD (B). $(R \leftrightarrow D=$ research and experimental development; $S A=$ South $A$ frica.$)$

received from foreign sources more than doubled in 2011/12 (ZAR118 million) from ZAR54 million in $2009 / 10$ and doubled again in 2013/14 and again in 2016/17 to reach ZAR512 million, equating to a 10 -fold increase over the past decade. The origins of these punctuated increases in foreign funding of government R\&D are not immediately clear, as they do not coincide with renewals of the US President's Emergency Plan for AIDS Relief (PEPFAR) programme. In comparison, foreign funding of science council internal $R \& D$ has stagnated in recent years, only increasing from ZAR417 million in 2009/10 to ZAR538 million in 2016/17, representing a decline of $1.9 \%$ per annum in real terms. Foreign funding of business sector R\&D also declined by $7.6 \%$ in real terms over this period, dropping from ZAR1.54 billion in 2009/10 to ZAR1.34 billion in 2016/17, although it still remains the largest recipient sector in absolute terms. Finally, NPO funding has shown significant although inconsistent increases and is now the third most important recipient sector of foreign funding after the business and higher education sectors, having surpassed the government and science council sectors in 2016/17 (ZAR640 million).

We briefly examined the exchange rateadjusted funding for R\&D from overseas (Fig. 6B). The ZAR/USD exchange rates over the period are not stable enough to infer any long-term dollar trends in the different sectors with confidence. However, our analysis did reveal that government sector foreign funding increased from USD7 million in 2009/10 to USD37 million in $2016 / 17$, science council foreign funding declined from USD55 million in 2009/10 to USD39.5 million in 2016/17, higher education foreign funding increased from USD58 million in 2009/10 to USD84 million in $2016 / 17$, business sector foreign funding declined from USD202 million in 2009/10 to USD98 million in $2016 / 17$, not-for-profit foreign funding increased from USD11 million in 2009/10 to USD47 million in 2016/17, and the dollar-denominated total foreign R\&D funding declined marginally from USD334 million in 2009/10 to USD306 million in 2016/17. These dollardenominated data should be interpreted with care, particularly in the context of post-financial crisis austerity coupled with a very low interest rate environment and weak stock market growth in the USA and Europe, which has meant that the funds available to the foreign agencies themselves have probably not increased significantly over this period. It is also important to remember that many research costs in SA, including salary costs, are incurred in rands, not dollars.

\section{Foreign-funded health research}

The large absolute increase in foreign funding of R\&D in SA since 2009/10 warrants further investigation to determine its impact on health research. Unfortunately, the data available in the DST's R\&D survey are not detailed enough for an analysis of foreign funds available specifically for health research in SA, although some crude estimates can be made for the higher education and science council sectors. According to the 2009/10 DST R\&D survey, foreign funding comprised $8.7 \%$ of total higher education institution expenditure on R\&D in 2009/10. In this year, total higher education expenditure on health research was ZAR1 196 million, so if the simplistic assumption is made that foreign funds were distributed as a constant proportion across all academic disciplines in the higher education sector, we can estimate that a total of ZAR104 million was available in foreign-funded health research in the higher education sector. Similarly, foreign funding comprised $12 \%$ of total science council in-house expenditure on $\mathrm{R} \& \mathrm{D}$ in $2009 / 10$, and the total science council in-house expenditure on health research was ZAR441 million, implying ZAR53 million 


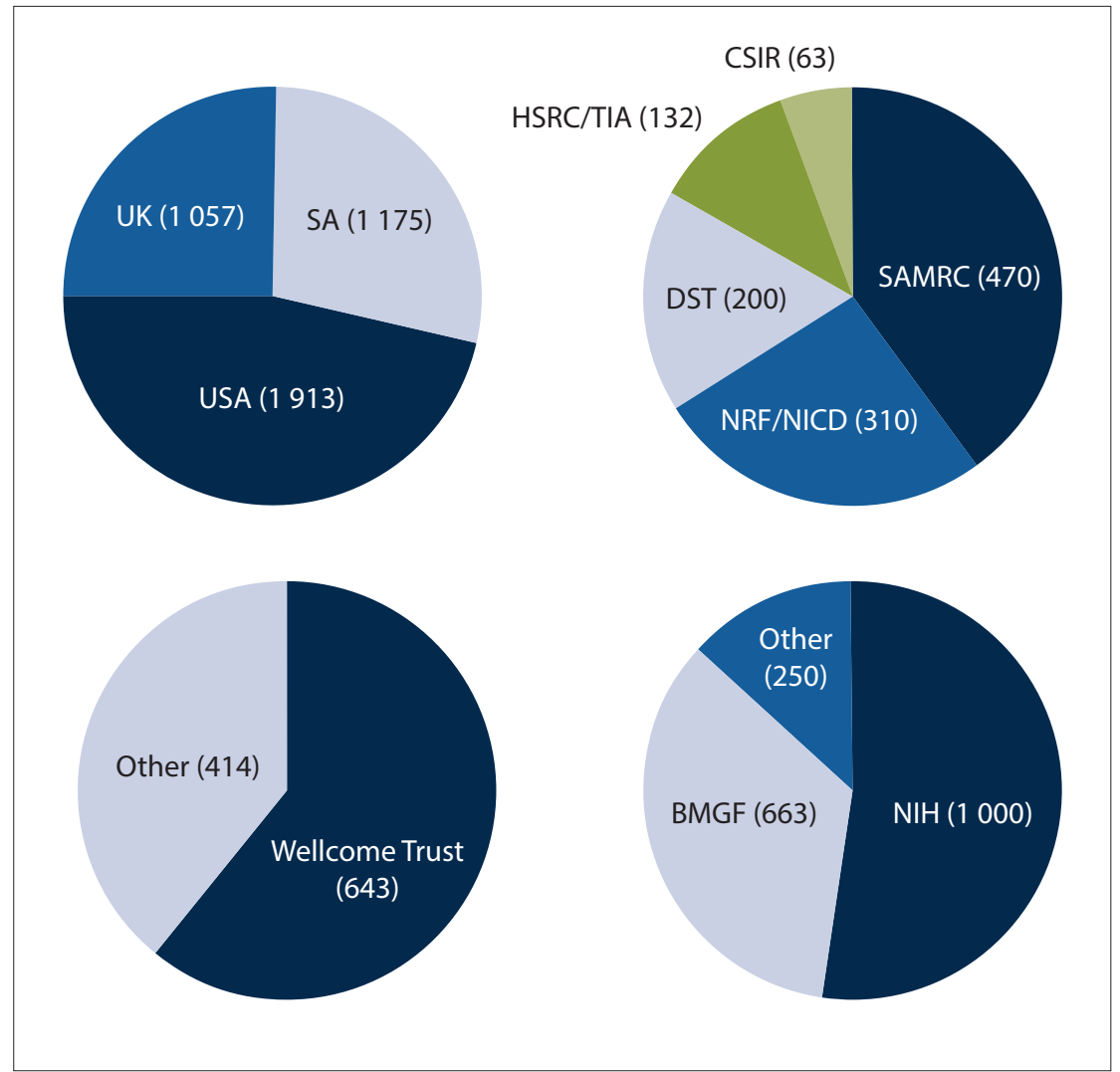

Fig. 7. Sources of local and foreign funding for health research in SA in 2017 (ZAR million). (A) Proportional funding from all funders by geographical source; (B) Proportional funding from SA government and science council sources; (C) Proportional funding from EU sources; (D) Proportional funding from US sources. $(S A=$ South Africa; $E U=$ European Union; SAMRC $=$ South African Medical Research Council; NRF = National Research Foundation; NICD = National Institute for Communicable Diseases; DST = Department of Science and Technology; HSRC = Human Sciences Research Council; $T I A=$ Technology Innovation Agency; CSIR = Council for Scientific and Industrial Research; 'Other' in (C) amalgamates Medicines for Malaria Venture, European and Developing Countries Clinical Trials Partnership, World Health Organization, Special Programme for Research and Training in Tropical Diseases, Department for International Development, UK, Horizon 2020, and Newton Fund/ Medical Research Council, UK; NIH = National Institutes of Health; BMGF = Bill and Melinda Gates Foundation; 'Other' in (D) amalgamates United States Agency for International Development (USAID) and Centers for Disease Control and Prevention.

foreign funding in health research in the science council sector that year. In 2016/17, foreign funding comprised $9.8 \%$ of total higher education institution expenditure on R\&D, and total higher education expenditure on health research was ZAR2.41 billion, implying ZAR236 million in foreignfunded health research in the higher education sector that year. Finally, foreign funding comprised $8.8 \%$ of total science council in-house expenditure on $R \& D$ in 2016/17, and total science council in-house expenditure on health research was ZAR837 million, implying ZAR74 million in foreignfunded health research in the science council sector. As a lower limit, ZAR157 million in foreign funds was therefore spent on health research by the combined higher education and science council sectors in
2016/17, increasing to ZAR2.3 billion that year if we include foreign funds flowing to NPOs (but ignoring funds flowing to industry), based on the same simplistic assumptions.

Considering that the DST's R\&D surveys provide a relatively coarse view of expenditure and are necessarily delayed in reporting, it was not possible to narrow down the magnitude of foreign funding of health research in SA between these upper and lower limits any further based on the DST data. We therefore sought to gain greater insight into current health research funding by asking 35 major national and international funders of health research in SA (supplementary Table S1, http://www.samj.org.za/public/sup/14349. doc) to provide non-confidential, aggregated secondary data on funding awards in SA, broken down where possible into distinct funding fields for HIV, tuberculosis (TB) and non-communicable diseases. In total, 30 of these organisations confirmed that they funded health research in SA, and 21 were able to provide the amounts funded. However, only $6(20 \%)$ could readily provide information relating to the allocation of these funds. Accepting the caveat that the resultant data are incomplete and may therefore underestimate the true totals, and noting also that we excluded funding for clinical trials conducted by multinational pharmaceutical companies from this analysis, we were able to estimate the total funding for health research in 2016/17, as well as the respective contributions of various foreign and local funding agencies (Fig. 7).

Out of a total of ZAR4.1 billion health research funding reported to us by the funders for 2016/17, local funders contributed ZAR1.18 billion (28.35\%), while foreign funding comprised $\sim$ ZAR2.98 billion: ZAR1.91 billion from the USA (46.15\%) and ZAR1.06 billion from the European Union (EU) (25.50\%). Usefully, the two different approaches we have taken here to estimate the magnitude of foreign funding of health research in SA in 2016/17 give numbers that are within a factor of 1.3 of each other, despite the limitations in the methodologies noted above, which provides increased confidence in the absolute numbers.

Our data reveal that the National Institutes of Health (NIH) was the biggest funder of health research in SA and provided $\sim$ ZAR1 billion alone in $2016 / 17,>60 \%$ of which was allocated to HIV or TB research (Table 3). The Bill and Melinda Gates Foundation was the second largest funder (ZAR663 million, including ZAR247 million allocated 


\begin{tabular}{ll} 
Table 3. National Institutes of Health funding of health \\
research in South Africa by disease area in $\mathbf{2 0 1 6 / 1 7}$ \\
\hline Disease area & \% of total funds \\
\hline AIDS and tuberculosis & 61 \\
Mental health & 8 \\
Drug and alcohol abuse & 4 \\
Cancer & 3 \\
Malaria & 2 \\
Cardiovascular diseases & 2 \\
Diabetes & 1 \\
Ageing & 1 \\
Others & 18
\end{tabular}

to HIV research, ZAR65 million to TB, and the remainder to other health-related research such as water and sanitation), followed by the Wellcome Trust, the SAMRC (ZAR470 million, including ZAR52 million for HIV research and ZAR61 million for TB research), and the National Research Foundation and National Institute for Communicable Diseases (ZAR310 million combined). These data point collectively to a significant skewing of health research funding in SA relative to the burden of disease, which is related in part to directed funding calls from foreign funding agencies in the infectious disease arena. However, it is also undoubtedly related to the fact that SA is the country with the highest prevalence and ongoing high incidence of HIV in its population, while being among the countries most affected by $\mathrm{TB}$, and to the large cohort of skilled investigators and capable institutions in SA, which together make it among the best places in the world to investigate HIV and TB.

\section{Discussion}

The analysis presented here reveals that the level of funding available for health research in SA in 2016/17 was in excess of ZAR4 billion, which is far higher than many researchers might realise. Moreover, it continues to increase. The widely held perception of a deficit in health research funds in SA may therefore result not from a true shortage of funds but rather from a narrow focus, leading to certain subfields or research entities receiving large amounts of funding while others struggle for grants. Notably, GERD has continued to increase steadily in absolute terms and, importantly, the percentage of GERD allocated to health research has increased significantly over the past decade and is now almost $20 \%$ of the total funds spent on R\&D in SA, in line with ASSAf's recommendations. In our previous analysis, we found that total health research investment across all sectors reached $0.15 \%$ GDP in $2009 / 10$. Here, we show that this value increased marginally to $0.16 \%$ in $2016 / 17$, but remains well below the ASSAf target of $0.4 \%$ GDP. Furthermore, aggregated government sector investment in health research as a percentage of the GDP $(0.033 \%$ in 2016/17) remains far below the NHRC's recommendation of $0.15 \%$ GDP. However, it is encouraging to find that, depending on narrower or broader definitions of health research, the $\mathrm{NDoH}$ invested between $1.7 \%$ and $3.6 \%$ of its budget (the 'Health Vote') in R4H in 2016/17, in line with at least some interpretations of the Ministry of Health's previous '2\%' commitments. ${ }^{[1-4]}$ In contrast, it remains far less clear what sums the nine pDoHs currently invest in health research each year, and it will be important to focus on this next. Since the pDoHs are largely responsible for implementation of health interventions, it seems logical that a portion of their annual budgets (which collectively totalled ZAR164 billion in 2016/17) should be allocated to research on health systems strengthening, epidemiology, social determinants of health and public health interventions, among others, in preparation for and as part of implementation of the impending National Health Insurance (NHI) programme. The NHRC therefore suggests that the pDoHs should have an audited line item for health research in their budgets in the future and that this be included in calculations of the aggregated government sector expenditure on health research.

Our analysis revealed a dramatic increase in foreign funds for health research in recent years. In 2016/17, excluding expenditure by foreign industry, foreign agencies were responsible for nearly ZAR3 billion in health research funding, equating to approximately three-quarters of all health research funds in SA, with US funders making up almost half and the EU another 25\%. Notably, the absolute magnitude of foreign funding of health research in $2016 / 17$, reported by the funders, suggests that in recent years, $>70 \%$ of foreign funding of R\&D in SA ( ZAR4.2 billion in 2016/17) was directed to health research.

Currently, the single biggest funder of health research in SA today is the NIH, a US agency. This is powerful testimony to the international competitiveness of health research in SA today, most notably in the fields of HIV and TB, as well as to successes in leveraging government expenditure through partnerships with foreign funders. However, considering a landscape in which $75 \%$ of health research funding in SA now comes from foreign sources, the dominance of international funding received in both absolute and relative terms compared with national funding also implies a critical dependence on health researchers competing successfully for foreign resources. As the leading causes of mortality in the country shift towards non-communicable diseases, it will therefore be imperative for SA investigators to be competitive for international funds in fields outside of HIV/TB research, so that health research in SA may continue to be directed to the burden of disease. It is important to note in this regard that foreign funders continue to create opportunities for investigators in many health research fields worldwide. Although these opportunities are driven by the funding organisations' priorities and funding levels, ultimately it is the bottom-up choices of the individual investigators as to what they apply for, as well as their competitive success, that determine the type and scale of foreign health research funding in SA.

An obvious limitation of this funding model is that it makes health research in SA very vulnerable to any changes in the policies of foreign organisations regarding support of investigators in SA. While we recognise the many other demands on SA's fiscus today, we therefore argue that sufficient and sustainable health research funding from national sources is essential in order to ensure that $\mathrm{R} 4 \mathrm{H}$ continues to contribute directly to the attainment of health equity and universal health coverage, as well as to the achievement of a long and healthy life for all, and thereby to economic prosperity. Sustainable financing of health research, with total investment and SA government investment in health research reaching $0.4 \%$ and $0.15 \%$ of the GDP, respectively, by 2030 , therefore forms one pillar of the NHRC's Integrated National Strategic Framework and Plan for Health Research in SA.

A key insight from our analysis is the lack of detailed information available from many funding agencies regarding the funding they provide in SA. The majority of funders we approached were not readily able to break down expenditure according to disease area, making it difficult to determine whether health research funding is currently aligned to the burden of disease or to identify gaps in funding for specific disease areas. Furthermore, it is clear that little communication occurs between funders, as our survey showed that it was not uncommon for several agencies to fund closely related 
projects and yet be unaware of other funding inputs. Apart from a handful of key players, few people have an accurate overview of the health research funding landscape at a national level. This lack of awareness may lead to misalignment of funding priorities and opportunities from both local and international agencies, which could be readily resolved by establishment of a funders' forum and a national priority health research fund in order to increase co-ordination, co-operation and co-funding between agencies.

Finally, our analysis shows that expenditure on health research by industry in SA has only grown by inflation in the period of this review, lagging behind the growth in health research expenditure by government, higher education, NPOs and foreign sectors. These insights indicate that the private sector, both locally and internationally, may hold important untapped potential that could be leveraged in the future. We therefore suggest that the development of a national strategy to incentivise new public-private partnerships in health research in SA could be mutually beneficial to both the country and companies. Building on the model of the Public Health Enhancement Fund, the government should encourage greater investment in health research by the private sector to enable, for example, precision medicine initiatives within the forthcoming NHI programme.

\section{Conclusions}

The overall health research funding landscape has changed significantly since our previous review, although the government's own commitments to health research funding remain unmet. In order to ensure sustainable local financing of health research, the SA government should adhere to the progressive targets set by the NHRC in the NDoH's Integrated National Strategic Framework for Health Research in South Africa (2017 - 2022) for total health research investment (targets: $0.18 \%$ GDP by 2021 and $0.4 \%$ GDP by 2030) and those for health research investments by the government sector (targets: $0.075 \%$ GDP by 2021 and $0.15 \%$ GDP by 2030) and the $\mathrm{NDoH}$ (targets: $1.1 \%$ of the consolidated government expenditure on health by 2021 and $2 \%$ by 2030). Targets should also be set now for health research expenditure by pDoHs, with a particular focus on funding for health systems research. Alongside these progressive targets, improved mechanisms to track $\mathrm{R} 4 \mathrm{H}$ expenditure across intersectoral boundaries and different government departments are urgently required to enable better alignment of funding priorities and to increase co-ordination and co-operation between science councils in health research funding.

\section{Declaration. None.}

Acknowledgements. This report is based on the work of the NHRC. We are grateful to Dr Mark Blecher (Treasury) for assistance with sources of information and to Mr Mpho Kgasi (NDoH) for secretarial support. We thank Steve Smith (former Health Attaché, US Consulate, SA) and Gray Handley (NIH) for helpful discussions. JMB thanks the National Research Foundation for a South African Research Chair.

Author contributions. MAB retrieved and analysed data and wrote the manuscript. RG conceptualised the study and collected and analysed data. GR and GL contributed to data collection and analysis. JMB conceptualised the study, analysed data, and wrote the manuscript. All authors read and approved the final version of the manuscript.

Funding. None.

Conflicts of interest. None.

1. Mexico Statement on Health Research. Knowledge for Better Health: Strengthening Health Systems. From the Ministerial Summit on Health Research, Mexico City, 16 - 20 November 2004. http://apps. who.int/gb/archive/pdf_files/EB115/B115_30-en.pdf (accessed 21 August 2018).

2. The Bamako call to action: Research for health. Lancet 2008;372(9653):1855. https://doi.org/10.1016/ S0140-6736(08)61789-4

3. The Algiers Declaration: Ministerial Conference on Research for Health in the African Region Narrowing the Knowledge Gap to Improve Africa's Health. Brazzaville, Congo: World Health Organization: Africa, 2008. https://apps.who.int/iris/bitstream/handle/10665/19990/AFR-RC58-12. Organization: Africa, 2008. https://apps. who.int/iris/bits
pdf? sequence= $=18$ risAllowed $=y$ (accessed 21 August 2018).

4. National Department of Health, South Africa. Health Research Policy in South Africa. Pretoria: 4. National Department of Health, South Africa. Health Research Policy in South Africa. Pretoria:
NDoH, 2001. https://www.gov.za/sites/default/files/gcis_document/201409/healthresearch0.pdf (accessed $\mathrm{NDoH}, 2001$. https://www.gov.za/sites/default/files/gcis_document/201409/healthresearch0.pdf (accessed
22 August 2018). 22 August 2018

5. Mayosi BM, Dhai A, Folb P, et al. Revitalising Clinical Research in South Africa: A Study on Clinical Research and Related Training. Pretoria: Academy of Science of South Africa, 2009. https://www.assaf. org.za/files/2009/09/ASSAf-Clinical-Report-2009.pdf (accessed 20 August 2018).

6. Paruk F, Blackburn JM, Friedman IB, Mayosi BM. National expenditure on health research in South Africa: What is the benchmark? S Afr Med J 2014;104(7):468-474. https://www.ajol.info/index.php/ samj/article/view/105629

7. Department of Science and Technology, South Africa. National Survey of Research and Experimental Development (2009/10 Fiscal Year). Pretoria: DST, 2012. http://www.hsrc.ac.za/en/research-outputs/ view/6239 (accessed 18 August 2018).

8. Department of Science and Technology, South Africa. National Survey of Research and Experimental Development (2016/17 Fiscal Year). Pretoria: DST, 2017. http://www.hsrc.ac.za/uploads/pageContent/8753/ SA\%20R\&D\%20SURVEY\%20STATISTICAL\%20REPORT\%20201516_WEB.pdf (accessed 18 August 2018). 9. National Treasury, Republic of South Africa. Estimates of National Expenditure 2013. http://www: treasury.gov.za/documents/national\%20budget/2013/ene/FullENE.pdf (accessed 24 August 2018).

10. National Treasury, Republic of South Africa. Estimates of National Expenditure 2014. http://www treasury.gov.za/documents/national\%20budget/2014/ene/FulleNE.pdf (accessed 24 August 2018).

11. National Treasury, Republic of South Africa. Estimates of National Expenditure 2017. http://www treasury.gov.za/documents/national\%20budget/2017/ene/FulleNE.pdf (accessed 24 August 2018).

12. National Treasury, Republic of South Africa. Estimates of National Expenditure 2018. http://www . National Treasury, Republic of South Africa. Estimates of National Expenditure 2018. http://ww
treasury.gov.za/documents/national\%20budget/2018/ene/FullENE.pdf (accessed 24 August 2018).

13. National Treasury, Republic of South Africa. Medium Term Budget Policy Statement 2010. http://www. National Treasury, Republic of South Africa. Medium Term Budget
treasury.gov.za/documents/mtbps/2010 (accessed 30 August 2018)

treasury.gov.za/documents/mtbps/2010 (accessed 30 August 2018).
4. National Treasury, Republic of South Africa. Medium Term Budget Policy Statement 2012. http://www. National Treasury, Republic of South Africa. Medium Term Budget

15. National Treasury, Republic of South Africa. Medium Term Budget Policy Statement 2017. http://www. . National Treasury, Republic of South Africa. Medium Term Budget
treasury.gov.za/documents/mtbps/2017 (accessed 30 August 2018).

treasury.gov.za/documents/mtbps/2017 (accessed 30 August 2018).
6. National Department of Health, South Africa. Annual Report 2016/17. Pretoria: NDoH, 2017. http:// ww. National Department of Health, South Africa. Annual Report 2016/17. Pretoria: NDoH, 2017. http://
(accessed 25 August 2018). (accessed 25 August 2018).

. World Health Organization. The WHO Strategy on Research for Health 2012. Geneva: WHO, 2012. https://www.who.int/phi/WHO_Strategy_on_research_for_health.pdf (accessed 2 September 2018). 8. United Nations Educational, Scientific and Cultural Organization (UNESCO) Institute for Statistics. Science, Technology and Innovation. http://data.uis.unesco.org/ (accessed 2 September 2018).

19. Commission on Health Research for Development. Health Research: Essential Link to Equity and Development. New York: Oxford University Press, 1990.

20. World Health Organization. Investing in Health Research and Development: Report of the Ad Hoc Committee on Health Research Relating to Future Intervention Options. Geneva: WHO, 1996. https:// apps.who.int/iris/handle/10665/63024 (accessed 24 February 2010).

21. South African Medical Research Council. Annual Report 2013/14. Cape Town: SAMRC, 2014. https:// www.samrc.ac.za/sites/default/files/attachments/2017-03-28/annualreport2013-14.pdf (accessed 20 August 2018).

Accepted 28 January 2020. 